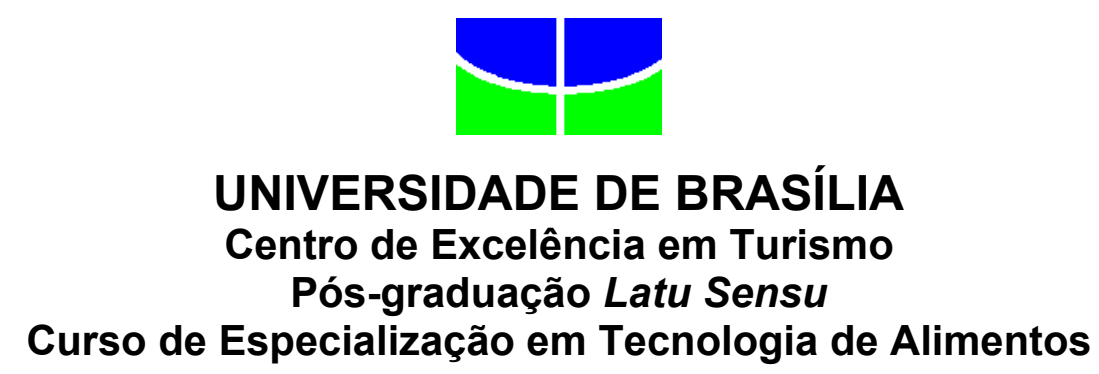

\title{
FERRAMENTAS DE GESTÃO DA SEGURANÇA DE ALIMENTOS: APPCC E ISO 22000 \\ (Uma Revisão)
}

Florence Marie Berthier

Ângela Patrícia Santana (Doutor) 


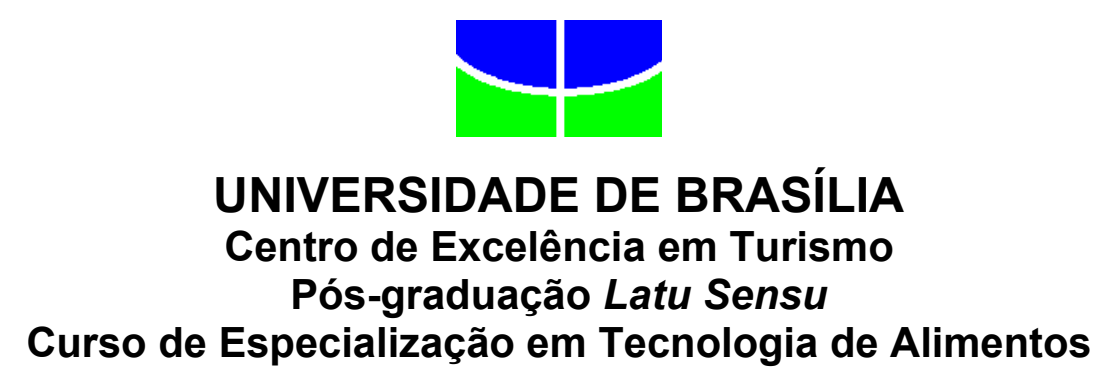

\section{FERRAMENTAS DE GESTÃO DA SEGURANÇA DE ALIMENTOS : APPCC E ISO 22000 (Uma Revisão)}

Florence Marie Berthier

Ângela Patrícia Santana (Doutor)

Monografia apresentada ao Centro de Excelência de Turismo - CET da Universidade de Brasília - UnB, como requisito parcial à obtenção do grau de Especialista em Tecnologia de Alimentos.

Brasília - 2007 


\section{UNIVERSIDADE DE BRASÍLIA}

Centro de Excelência em Turismo

Pós-graduação Latu Sensu

Curso de Especialização em Tecnologia de Alimentos

Florence Marie Berthier

Aprovado por:

Professor orientador: Ângela Patrícia Santana

Professor: Luiz Antônio Borgo

Professor: Luciane Cardoso

Brasília, 07 de março de 2007 


\section{DEDICATÓRIA}

Dedico este trabalho aos meus amados filhos Tomás e Matias, e ao meu querido marido Porfírio, Toth, pelo amor, apoio e compreensão. 


\section{RESUMO}

A crescente busca por alimentos seguros no mercado atual forçou indústrias de alimentos a obter formas de controles mais apurados para fabricação de produtos livres de contaminações. Muitas causas de contaminação são provenientes da falta de aplicação de procedimentos de limpeza e de conscientização das pessoas que manipulam os alimentos. Com este estudo, pretendeu-se revisar as principais ferramentas de gestão da segurança de alimentos disponíveis no mercado e fazer uma abordagem no que há de mais recente em gestão de segurança de alimentos, a norma ISO 22.000. O sistema APPCC estabelece um sistema de controle com foco na prevenção em vez de confiar basicamente nas análises de produto final, e deve ser capaz de se ajustar à mudanças. Referente à ABNT NBR ISO 22000, é aconselhável que ocorra comunicação interativa ao longo de toda a cadeia alimentar, sejam implementadas boas práticas de fabricação (ou pré-requisitos) bem como o controle de perigos (APPCC), além dos requisitos de sistemas de gestão, comuns a qualquer sistema de gestão. No Brasil, há poucos relatos sobre a utilização dessas ferramentas em indústrias de produtos de origem animal, salvo as exportadoras que devem contemplar exigências externas e as leis brasileiras. Muitos casos da não utilização são devidos ao ineficiente mecanismo de fiscalização existente no País e à falta de informação e responsabilidade de empresários.

Palavras chaves: Ferramentas de gestão 1, Segurança de alimentos 2, APPCC 3, ISO 220004. 


\begin{abstract}
The growing demand for safe foods in recent times, forced the food industries to create more efficient controls to obtain products without contamination. Many causes of contamination are originated from the lack of applications to towards cleaning procedures and awareness of people who manipulate foods. The present study intended to review the principals tools of food safety management available in the market and make an approach in what is most recent about food safety management, the norm ISO 22000. The HACCP established a control system with a focus in the prevention instead of trusting only in analysis of the final product, and be able to adjust in changes. Referring to ABNT NBR ISO 22000 it's recommended that an interactive communication through the entire food chain could be implemented by good practices of fabrication (or pre requirements) as well as the danger controls (HACCP), beyond the system management requirements, common in any management system. In Brazil, there are few reports of the use of this tools in industries of animal origin product, except for the exporters who must contemplate external requirements and the Brazilian laws. In many cases of the no utilization are due to the lack of control mechanism in the country and the lack of information and responsibility of entrepreneurs.
\end{abstract}

Keywords: Management tools 1, Food Safety 2, HACCP 3, ISO 220004. 


\section{LISTA DE ILUSTRAÇÕES}

Ilustração 1- Planejamento de Alimento Seguro 


\section{SUMÁRIO}

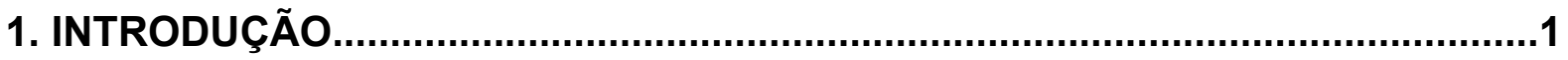

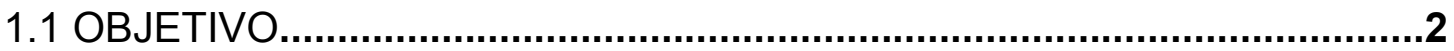

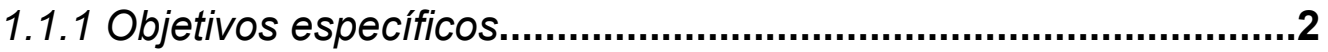

2. METODOLOGIA

3. REVISÃO LITERÁRIA

3.1 QUALIDADE E SEGURANÇA DOS ALIMENTOS.....................................4

3.2 FERRAMENTAS DE GESTÃO DA SEGURANÇA DE ALIMENTOS...........5

3.2.1 Codex Alimentarius...................................................................

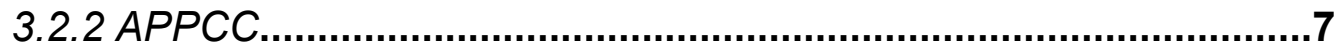

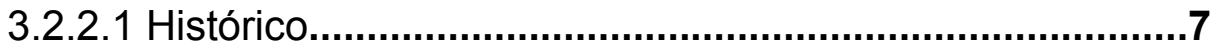

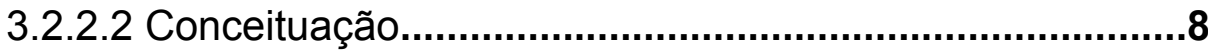

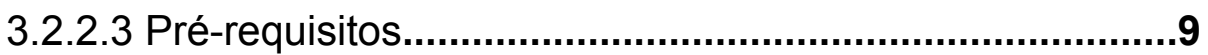

3.2.2.4 O Sistema APPCC............................................................

3.2.2.5 Procedimentos preliminares...........................................12

3.2.2.6 Aplicação do APPCC.....................................................13

3.2.2.7 Implementação do APPCC.............................................14

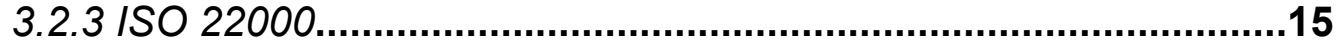

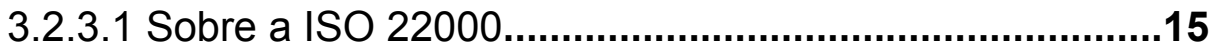

3.2.3.2 Cadeia produtiva e processo.........................................16

3.2.3.3 Requisitos gerais......................................................16

3.2.3.4 Responsabilidade da direção.........................................17

3.2.3.5 Gestão de recursos...................................................17

3.2.3.6 Planejamento e realização de produtos seguros............18

3.2.3.6.1 Análise de perigos...........................................18

3.2.3.6.2 Estabelecimento dos pré-requisitos

operacionais .19

3.2.3.6.3 Estabelecimento do plano APPCC...................19

3.2.3.6.4 Atualização de informações preliminares e documentos que especificam os PPR e o plano APPCC. 
3.2.3.6.5 Planejamento da verificação..............................20

3.2.3.6.6 Sistema de rastreabilidade..............................21

3.2.3.7 Validação, verificação e melhoria de gestão da

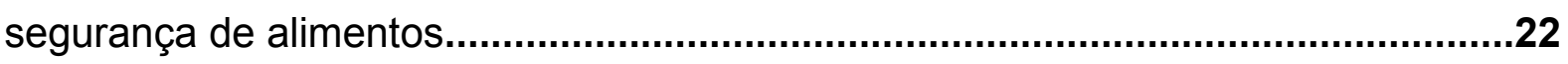

4. CONCLUSÃO

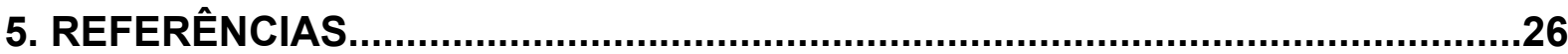




\section{INTRODUÇÃO}

A garantia da qualidade na alimentação é atualmente o desejo dos consumidores em todo mundo. Por existir maior disponibilidade de informações sobre seus direitos, verificamos um grau crescente de exigências das pessoas. Por isso, cada vez mais, as empresas do setor de alimentos têm buscado assegurar a qualidade de seus produtos e serviços (DIAS, 1999).

Alguns parâmetros importantes, como a qualidade da matéria-prima, padronização do processamento e a manutenção das temperaturas nas saídas da indústria até as gôndolas do supermercado, têm sido observadas mais atentamente para se evitar as toxinfecções alimentares (FELIX et al., 2003).

Nos Estados Unidos e em alguns países da Europa, muitos esforços têm sido feitos para evitar a propagação de agentes patogênicos, porém os altos índices de ocorrência de surtos de toxinfecção alimentar indicam ausência de controles sistemáticos que garantam permanentemente a segurança sanitária desejável (FDA, 1997). No Brasil, a ocorrência de doenças transmitidas por alimentos (DTA) não é de notificação compulsória, ou seja, de comunicação obrigatória às autoridades sanitárias, o que compromete a real avaliação do problema (SENAI, 2000).

Ferramentas de gestão da qualidade têm sido criadas e implementadas para garantir um alimento seguro, além de proporcionar diminuição de custos, redução de perdas e otimização da produção (FURTINI; ABREU, 2005). As Boas Práticas de Fabricação (BPF) e o Sistema APPCC (Análise de Perigos e Pontos Críticos de Controle) são ferramentas amplamente recomendadas por órgãos de fiscalização tais como a Agência Nacional de Vigilância Nacional - ANVISA e o Ministério da Agricultura, Pecuária e Abastecimento - MAPA, e utilizada em toda cadeia produtiva de alimentos. Recentemente, a Associação Brasileira de Normas Técnicas - ABNT disponibilizou o Guia de aplicação da ABNT NBR ISO 22000:2006 baseada nos princípios do APPCC para promover a eficácia e a eficiência de um sistema de gestão de segurança de alimentos.

Quando se fala em indústria de alimentos, é interessante ressaltar que muitas causas de contaminação são provenientes da falta de aplicação de procedimentos de limpeza e de conscientização das pessoas que manipulam os alimentos 
(CARBALLIDO ${ }^{1}$ et al., 1994 apud FIGUEIREDO; COSTA NETO, 2001). O treinamento e o comprometimento de todos os envolvidos na fabricação, principalmente, e com destaque, a alta administração, são uma das condições básicas para o sucesso da implantação dessas ferramentas (FIGUEIREDO; COSTA NETO, 2001).

Rocha, 2006, realizou um estudo regional no qual foram visitadas quatro agroindústrias e nenhuma delas havia implantado as BPF. A implementação do Sistema APPCC no Brasil está caminhando em busca da qualidade, porém ainda está muito aquém do que poderia estar. Mesmo como adequação progressiva sugerida pela legislação, as dificuldades encontradas para tal procedimento e a falta de conhecimento do Sistema são consideradas empecilho para conduta definitiva dos empresários principalmente de indústrias de médio e pequeno porte (SENAI, 2000).

Tendo em vista a importância das ferramentas de gestão da qualidade na segurança dos alimentos, este trabalho teve por objetivo avaliar detalhadamente os princípios dos sistemas mencionados bem como abordar o que há de mais recente em gestão de segurança de alimentos, a ISO 22000.

\subsection{OBJETIVO}

O presente estudo pretende promover uma revisão bibliográfica de alguns sistemas de gestão da segurança dos alimentos propriamente dito, bem como seus princípios e formas de aplicação.

\subsubsection{Objetivos específicos}

- Comparar os princípios do APPCC e ISO 22000.

\footnotetext{
${ }^{1}$ CARBALLIDO, J.R.; VIYELLA, A.R. \& MORENO, I.J.: "Exigências de calidad em las empresas alimentarias: industria carniça” Alimentaria, Enero-Febrero, p. 23-26, 1994.
} 


\section{METODOLOGIA}

O método de abordagem aplicado no presente estudo é a pesquisa bibliográfica desenvolvida a partir de materiais tais como livros, artigos científicos, publicações periódicas, legislação brasileira e documentos eletrônicos visando assim uma revisão de trabalhos científicos e publicações já existentes.

Para concretizar os objetivos, o presente trabalho foi dividido em 3 capítulos. O presente capítulo introdutório trouxe uma breve contextualização do problema apontando a importância da qualidade, além da justificativa e objetivos. O capítulo seguinte apresenta conceitos e ferramentas de gestão da segurança de alimentos e a evolução dos conceitos de implantação. Finalmente, a conclusão aponta o incremento ao modelo de norma internacional atual em relação ao que já existe e as limitações para se implementar tais ferramentas. 


\section{REVISÃO LITERÁRIA}

\subsection{QUALIDADE E SEGURANÇA DOS ALIMENTOS}

O conceito de qualidade de alimentos, na visão do consumidor, nada mais é do que a satisfação de características como sabor, aroma, aparência, embalagem, preço e disponibilidade (WURLITZER, 2007). Para o Novo Dicionário Aurélio da Língua Portuguesa, numa escala de valores, a qualidade permite avaliar e, conseqüentemente, aprovar, aceitar ou recusar determinado tipo de produto.

A segurança de alimentos é segurança de que o consumo de um determinado alimento não causa dano a um consumidor quando preparado ou consumido de acordo com seu uso intencional (CODEX ALIMENTARIUS, 1999).

A globalização da economia brasileira e a abertura do mercado interno ao comércio internacional, condicionam as indústrias a atingirem patamares mais elevados de flexibilização e especialização, direcionadas para o atendimento ao cliente (THRUN, 2003). É razoável que se pense que a prioridade das estratégias da gestão da qualidade é promover melhorias contínuas no seu processo produtivo. Mas deve-se ter em mente, sempre, que tais melhorias objetivam desenvolver um melhor atendimento ao cliente (PALADINI ${ }^{2}, 1995$ apud THRUN, 2003).

A higienização em uma indústria de alimentos merece um destaque especial. Casos de alterações de produtos alimentares e de contaminações inaceitáveis, envolvendo custos, têm sido atribuídos à falhas ou insuficiência desses procedimentos (THRUN, 2003).

$\mathrm{Na}$ direção de conceitos qualidade oferecida, Mann ${ }^{3}, 1992$ (apud THRUN, 2003) defende que uma empresa que se preocupa com a qualidade em seus produtos, tem como resultado uma reação em cadeia, custos mais baixos, melhor posição competitiva, pessoas mais felizes no trabalho e mais empregos. A produtividade aumenta à medida que a qualidade melhora, pois há menos retrabalhos e desperdícios.

\footnotetext{
${ }^{2}$ PALADINI, E.P.: Gestão da qualidade no processo: a qualidade na produção de bens e serviços. São Paulo: Atlas, 1995. p. 57-61.

${ }^{3}$ MANN, N. R. D.: as chaves para excelência. São Paulo. Makron, McGrow-Hie. 1992
} 


\subsection{FERRAMENTAS DE GESTÃO DA SEGURANÇA DE ALIMENTOS}

\subsubsection{Codex Alimentarius}

O Codex Alimentarius é um fórum internacional de normalização de alimentos estabelecido pela Organização das Nações Unidas por meio da Food and Agriculture Organization - FAO e Organização Mundial de Saúde - OMS, criado em 1963, com a finalidade de proteger a saúde dos consumidores e assegurar práticas eqüitativas no comércio regional e internacional de alimentos (BRASIL, 2006).

As normas Codex abrangem os principais alimentos, sejam estes processados, semiprocessados ou crus; também abrangem substâncias/produtos que são usadas para a elaboração dos alimentos, na medida em que seja necessário para alcançar os principais objetivos do Codex. As diretrizes Codex referem-se aos aspectos de higiene e propriedades nutricionais dos alimentos, abrangendo, código de prática e normas de: aditivos alimentares, pesticidas e resíduos de medicamentos veterinários, substâncias contaminantes, rotulagem, classificação, métodos de amostragem e análise de riscos. Desde a sua criação, o Codex gerou investigações científicas sobre os alimentos e contribuiu para que aumentasse consideravelmente a consciência da comunidade internacional acerca de temas fundamentais, como a qualidade e inocuidade dos alimentos e a saúde pública (BRASIL, 2006).

Os padrões de segurança alimentar são definidos no acordo para Aplicação de Medidas Sanitária e Fitosanitárias - SPS da Organização Mundial do Comércio OMC como aqueles relacionados com os aditivos alimentares, as drogas veterinárias e resíduos de pesticidas, os contaminantes, os métodos de análise e de amostragem e os códigos e manuais de Práticas de Higiene. Esses padrões são usados como referência pela OMC (SENAI, 2000).

A higiene dos alimentos representa a maior atividade do Codex desde o estabelecimento do Comitê do Codex Alimentarius - CCA. Como a Higiene dos Alimentos é mais bem controlada na etapa de produção e processamento, o principal objetivo deste comitê tem sido as Práticas de Higiene ao invés dos padrões microbiológicos do produto acabado (SENAI, 2000). Em 1997, o Codex adotou a aplicação do sistema de Análise de Perigos e Pontos Críticos de Controle, o APPCC, 
como ferramenta importante para identificar perigos e estabelecer um esquema de controle. A prevenção é a base da norma (SENAI, 2000).

O trabalho da Comissão do Codex Alimentarius (incluindo a "Norma para a Aplicação de Análise de Perigos e Pontos críticos de Controle - APPCC") tornou-se referência para os requisitos internacionais de segurança alimentar. Assim é de grande importância que as normas Codex para aplicação do APPCC sejam consideradas para que não ocorram conflitos, no que se refere à Segurança dos Alimentos (SENAI, 2000).

O Sistema APPCC é recomendado por organismos internacionais como a OMC (Organização Mundial do Comércio), FAO (Organização das Nações Unidas para Alimentação e Agricultura), OMS (Organização Mundial de Saúde) e pelo MERCOSUL e é exigido pela Comunidade Européia e pelos Estados Unidos. No Brasil, o Ministério da Saúde e o Ministério da Agricultura e Abastecimento já têm ações com objetivo de adoção do Sistema APPCC pelas Indústrias Alimentícias (MAPA, 2005).

A Agência Nacional de Vigilância Sanitária - ANVISA participa, conveniada ao SENAI, do Projeto APPCC (Análise de Perigos e Pontos Críticos de Controle), desenvolvido para garantir a produção de alimentos seguros à saúde do consumidor (BRASIL, 2006). Uma das ações do projeto é a criação do Sistema APPCC, que tem como pré-requisitos as Boas Práticas de Fabricação e a Resolução RDC $n^{\circ} 275$, de 21 de outubro de 2002 sobre Procedimentos Padrão de Higiene Operacional (PPHO). Esses pré-requisitos identificam os perigos potenciais à segurança do alimento desde a obtenção das matérias-primas até o consumo, estabelecendo em determinadas etapas (Pontos Críticos de Controle) medidas de controle e monitorização que garantam, ao final do processo, a obtenção de um alimento seguro e com qualidade (BRASIL, 2006). O Sistema APPCC contribui para uma maior satisfação do consumidor, torna as empresas mais competitivas, amplia as possibilidades de conquista de novos mercados, nacionais e internacionais, além de propiciar a redução de perdas de matérias-primas, embalagens e produto (BRASIL, 2006).

O sistema APPCC está designado para ser implantado em nível de produção, transformação, transporte, distribuição, armazenamento, exposição à venda, consumo ou qualquer outra etapa que represente um risco à segurança do produto. Envolve, portanto, a produção primária, as indústrias, os consumidores, os 
transportadores, os inspetores/fiscalizadores, os importadores/exportadores e os fornecedores de produtos e serviços de qualquer natureza que se relacione com a segurança do produto: embalagens, rotulagem, agentes de limpeza e desinfecção, fornecedores de equipamentos, engenheiros projetistas de áreas físicas e de equipamentos, empresas de controle de insetos e roedores, manipuladores de alimentos, funcionários da empresa, trabalhadores rurais e outros, de forma a identificar, caracterizar, adotar medidas preventivas de controle e efetivamente controlar os perigos possíveis dos produtos alimentícios (SILVA JR, 2001).

Contaminações na indústria de produtos de origem animal promovem alterações no valor nutricional e nas características sensoriais em seus produtos. Além disso, o processamento inadequado favorece a colonização dos tecidos por microrganismos deteriorantes e patogênicos. Com a aplicação do Sistema APPCC é possível atingir condições ideais de processamento e conservação, promovendo assim a produção de um alimento seguro e com maior tempo de vida de prateleira (BORGES; FREITAS, 2002)

\subsubsection{APPCC}

\subsubsection{Histórico}

O Sistema APPCC originou-se na Indústria Química, na Grã-Bretanha, nos anos 50, 60 e 70, utilizado extensivamente em projetos de plantas de energia nuclear. No início dos anos 60, a NASA dos Estados Unidos, estabeleceu o estudo da segurança da saúde dos astronautas como prioridade no intuito de eliminar possíveis toxinfecções durante a permanência no espaço (SENAI, 2000). A Companhia Pillsbury desenvolveu sistemas de controles mais efetivos para o processamento dos alimentos, observando em cada etapa o que pode sair errado (FMEA "Failure, Mode and Effect Analysis"), garantindo alimentos seguros para o programa espacial da NASA.

Em 1971, o Sistema serviu como base para a Administração de Alimentos e Medicamentos (FDA) desenvolver a regulamentação legal para a elaboração de alimentos de baixa acidez e em 1973 publicou-se o primeiro documento sobre o APPCC, como base para treinamentos de inspetores do FDA. 
Em 1985, a Academia Nacional de Ciências dos Estados Unidos recomenda o uso do Sistema APPCC em programas de proteção dos alimentos. Em 1988 editouse um livro pela Comissão Internacional de Especificações Microbiológicas para Alimentos - ICMSF, propondo o APPCC como ferramenta de qualidade referente à higiene e microbiologia; já em 1993, a Comissão do Codex Alimentarius incorporou o "Guidelines for the application of the HACCP System" (SENAI, 2000).

No Brasil, a legislação referente ao APPCC teve início em 1993 estabelecendo pelo SEPES/MAARA normas e procedimentos para pescados, e, no mesmo ano a Portaria 1428 do Ministério da Saúde - MS preconiza normas para obrigatoriedade em todas as indústrias de alimentos. Em 1997 foram estabelecidas as Diretrizes Codex para a aplicação do Sistema (SENAI, 2000). A Portaria 46 do Ministério da Agricultura, Pecuária e Abastecimento (1998), obrigou a implantação gradativa de todas as indústrias de produtos de origem animal do programa de qualidade APPCC, cujos pré-requisitos essenciais são as BPF (FURTINI; ABREU, 2006). As empresas exportadoras de carnes para União Européia e Canadá, segue a Circular 369/2003 que dá as instruções para elaboração e implantação dos sistemas PPHO e APPCC até junho de 2003. Os estabelecimentos da Lista Geral de exportadores deverão aplicar o plano PPHO até janeiro de 2004, sendo o plano APPCC de implantação voluntária. O plano PPHO também é obrigatório para entrepostos-frigoríficos exportadores. As empresas devem passar pelas auditorias semestrais da Divisão de Controle do Comércio Internacional (DCl) e pela avaliação dos planos pelo Sistema de Inspeção Federal.

\subsubsection{Conceituação}

O conceito de APPCC permite um estudo sistemático para identificar perigos, avaliar a probabilidade deles acontecerem durante o processamento, distribuição ou uso do produto e definir meios para controlá-los (ILSI ${ }^{4}, 1997$ apud FIGUEIREDO; COSTA NETO, 2001).

Segundo Silva Jr (2001) é um Sistema que deve ser entendido e implementado adequadamente, pois é um Sistema que:

- é preventivo,

\footnotetext{
${ }^{4}$ ILSE (International Life Science Institute): A simple guide to understanding and applying the hazard analysis critical control point concept. $2^{\text {nd }}$ edition, 1997.
} 
- é uma ferra menta de gerenciamento usado para proteger os produtos alimentícios contra perigos microbiológicos, químicos e físicos,

- tem base científica e o reconhecimento da existência ou não de formas seguras de controle de perigos,

- não é de risco zero; tem por objetivo reduzir os riscos dos perigos relacionados aos alimentos,

- é aplicável em toda cadeia alimentar,

- é um sistema que busca controlar as etapas que estão associadas dramaticamente com perigos não controláveis ou incontroláveis, visando a segurança do produto e a proteção do consumidor.

Da sigla APPCC, a Análise de Perigos - AP é, sem dúvida, a peça chave para todo o sistema, principalmente para a determinação dos Pontos Críticos de Controle - PCC (FURTINI; ABREU, 2005). Os perigos variam quanto ao grau de severidade e riscos potenciais de manifestação em consumidores, além de serem específicos para cada produto. O PCC é qualquer ponto, etapa ou procedimento no qual se aplicam medidas de controle (preventivas) para manter um perigo significativo sob controle, com objetivo de eliminar, prevenir ou reduzir os riscos à saúde do consumidor (SENAI,2000). Já o Ponto de Controle (PC) é qualquer ponto ou etapa ou procedimento no qual fatores biológicos, químicos ou físicos podem ser controlados, prioritariamente por programas e procedimentos de pré-requisitos, como as Boas Práticas (CNC/CNI/SEBRAE/ANVISA, 2001).

A presença de resíduos químicos oferece grande ameaça, principalmente quando analisados os efeitos no longo prazo. A contaminação microbiológica conhecida como a mais ameaçadora à saúde humana pode ser bastante controlada, pelas Boas Práticas de Higiene, durante o manuseio e processamento dos alimentos, enquanto a contaminação química é em geral bastante difícil de ser controlada (BARENDZ 5 , 1998 apud FIGUEIREDO; COSTA NETO, 2001).

\subsubsection{Pré-requisitos}

Para que o APPCC funcione de modo eficaz, deve ser acompanhado de programas de pré-requisitos que fornecerão as condições operacionais e ambientais

\footnotetext{
${ }^{5}$ BARENDZ, A.W.: "Food safety and total quality management." Food Control, vol. 9, n 2-3, 1998.
} 
básicas necessárias para a produção de alimentos inócuos e saudáveis (OPAS, 2000). As ferramentas de gestão da qualidade como $5 \mathrm{~S}$, e garantia da qualidade (BPF, PPHO e POP), embora consideradas de caráter genérico são indispensáveis para o sistema APPCC e devem ser executadas sobre uma base sólida de cumprimento (FURTINI; ABREU, 2005).

As BPFs são necessárias para controlar as possíveis fontes de contaminação cruzada e garantir que o produto atenda às especificificações de identidade e qualidade (SENAI, 2000).

Segundo a legislação, os seguintes aspectos devem ser contemplados no Programa de Boas Práticas de Fabricação:

- projetos dos prédios e instalações - facilidade de limpeza, operações sanitárias e fluxos lógicos;

- limpeza e conservação de instalações hidráulicas, pisos e paredes, terrenos, instalações elétricas e isolamentos, tratamento de lixo;

- programa de qualidade da água - potabilidade da água;

- recebimento de matérias-primas e estocagem - áreas apropriadas para estoque de matéria-prima, embalagens, produto acabado, produtos químicos e insumos;

- qualidade da matéria-prima e ingredientes - deve-se conhecer o grau de contaminação de cada matéria-prima e ingrediente. Inclui especificações de produtos e seleções de fornecedores;

- higiene pessoal - higiene corporal, controle de doenças, uso de uniformes, toucas e calçados limpos e adequados, evitar atitudes não higiênicas;

- controle integrado de pragas;

- projeto sanitário dos equipamentos;

- limpeza e sanificação de equipamentos e utensílios;

- calibração dos instrumentos - deve-se proceder à calibração periódica dos instrumentos de controle de temperatura, pressão, peso e outros parâmetros relacionados à segurança do produto;

- programa de recolhimento (recall) - procedimentos escritos para assegurar o recolhimento do lote de um produto de forma eficiente, rápida e completa;

- garantia e controle de qualidade - atividades que complementam as BPF;

- treinamentos periódicos para os funcionários, tornando-os responsáveis e comprometidos com a qualidade dos serviços. 
Os Procedimentos Padrão de Higiene Operacional - PPHO representam um programa escrito a ser desenvolvido, implantado, monitorado, registrado e verificado pelos estabelecimentos, para se tomar ações corretivas (SENAI, 2000). Os Procedimentos Operacionais Padronizados - POP instituídos pela resolução 275 de 2002, pela Anvisa (MS), vão um pouco além do controle da higiene, porém não descaracterizam os PPHO recomendados pelo MAPA; ambos vão dar suporte à confecção do manual de boas práticas:

PPHO:

1) Potabilidade da água

2) Higiene de Superfícies de contato com o produto

3) Prevenção de contaminação cruzada

4) Higiene Pessoal

5) Proteção contra contaminação/adulteração do produto

6) Identificação e estocagem adequada dos produtos tóxicos

7) Saúde dos Operadores

8) Controle Integrado de Pragas

POP:

1) Higienização das instalações, equipamentos, móveis e utensílios

2) Controle da potabilidade da água

3) Higiene e saúde dos manipuladores

4) Manejo dos resíduos

5) Manutenção preventiva e calibração de equipamentos

6) Controle integrado de vetores e pragas urbanas

7) Seleção das matérias-primas, ingredientes e embalagens

8) Programa de recolhimento de alimentos

\subsubsection{O Sistema APPCC}

Para uma correta aplicação do sistema APPCC, é muito importante conhecer as definições e o significado exato dos princípios do APPCC. A metodologia é lógica, ordenada e possui sete princípios, por meio dos quais pode-se controlar os perigos para a saúde dos consumidores. Estes são aplicados na seguinte seqüência, de maneira organizada e sistemática (FELIX et al, 2003):

Princípio 1: Realizar uma análise de perigos. 
Princípio 2: Determinar o ponto crítico de controle (PCC).

Princípio 3: Estabelecer limites críticos.

Princípio 4: Estabelecer um sistema de controle para monitorar o PCC.

Princípio 5: Estabelecer as ações corretivas a serem tomadas quando o monitoramento indicar que um determinado PCC não está sob controle.

Princípio 6: Estabelecer procedimentos de verificação para confirmar se o sistema APPCC está funcionando de maneira eficaz.

Princípio 7: Estabelecer a documentação sobre todos os procedimentos e registros apropriados a estes princípios e sua aplicação.

O sistema APPCC segundo o Codex, aborda somente a inocuidade do alimento e não as operações cotidianas da planta, que envolvem qualidade, aspectos econômicos e questões regulamentares. O conceito de APPCC aplica-se a todos os estágios da cadeia de produção do alimento, desde o plantio, cultivo, colheita, processamento, criação animal, fabricação, distribuição e comercialização até o preparo do alimento para consumo. Recomenda-se a adoção, a mais completa possível do APPCC por toda a cadeia alimentar para obter um produto inócuo ao consumidor (OPAS, 2001).

\subsubsection{Procedimentos preliminares}

A primeira situação a ser definida é o comprometimento da alta direção, a partir daí os supervisores envolvidos devem estar cientes do grau de importância do Sistema e dos benefícios que possa trazer para a empresa (SENAI, 2000). Disponibilizar recursos para aquisição de equipamentos, sanitizantes, material de pesquisa é um dos fatores que contribuem para o sucesso do Sistema (FURTINI; ABREU, 2005).

Um profissional competente, treinado e com facilidade de trabalhar em equipe deve liderar o programa. A formação da equipe multidisciplinar com representantes de diversas áreas deve também compor pessoal que está diretamente envolvido no processamento do alimento, pela vivência com a prática da indústria (SILVA JR, 2001; SENAI, 2000; FURTINI; ABREU, 2005).

O grande desafio é o treinamento e capacitação do pessoal nesse Sistema. Faz parte deste desafio o fato do mesmo ser um sistema que se aprende e se aperfeiçoa fazendo. Deve existir uma atividade de equipe, com chefes, supervisores, 
e os que efetivamente realizam uma determinada etapa do processo, com objetivos comuns, para que em situações de risco, a decisão deve ser tomada de imediato para a retomada do controle, sem aguardar instruções (SILVA JR, 2001).

Um "Programa de Capacitação Técnica" deve ser incluso no plano APPCC para reciclar e atualizar todos os colaboradores (SENAI, 2000).

\subsubsection{Aplicação do APPCC}

Aqui se apresenta o procedimento para a aplicação do sistema APPCC em uma planta produtora ou manipuladora de alimentos. Uma seqüência lógica completa para a aplicação do APPCC deve ter:

1) Definição dos objetivos

2) Identificação e organograma da empresa

3) Avaliação de pré-requisitos (exigência do MAPA)

4) Programa de capacitação técnica (exigência do MAPA)

5) Descrição do produto e uso esperado e os possíveis consumidores.

6) Construir o fluxograma

7) Verificar o fluxograma no local

8) Analisar os perigos

9) Relacionar todos os perigos potenciais (identificar os perigos)

10)Avaliar todos os perigos potenciais (avaliar os riscos)

11)Determinar a necessidade de ações

Em seguida, entram, como citado anteriormente, os sete princípios:

verificar através de quais medidas os perigos (significativos) podem ser evitados, eliminados ou reduzidos a um nível aceitável (Princípio 1); Determinar o(s) PCC (Princípio 2); Estabelecer o limite crítico para cada PCC (Princípio 3); Estabelecer um sistema de monitoramento para cada PCC (Princípio 4); Estabelecer ações corretivas para os desvios que possam ocorrer (Princípio 5); Estabelecer os procedimentos de verificação (Princípio 6); Estabelecer métodos de manutenção de registro e da documentação (Princípio 7).

O gerenciamento da inocuidade alimentar incorpora aspectos toxicológicos, microbiológicos, médicos e epidemiológicos; a aplicação adequada do APPCC requer especialistas com grau elevado de experiência científica, bem como 
capacidade de pensar de forma estruturada e sistemática para aplicar os elementos do gerenciamento de inocuidade de modo inteligente e eficaz (OPAS, 2001).

A descrição do produto não se restringe à aparência e à estrutura, ou às matérias-primas e aos aditivos usados para sua produção. Os fatores que influenciam na cinética dos microrganismos, como $\mathrm{pH}$ e atividade de água (Aw), assim como as condições de armazenamento (embalagem em atmosfera modificada, temperatura) e a vida útil prevista devem também ser definidos (OPAS, 2001).

O uso esperado consiste em informações sobre se o produto tem que ser preparado antes do consumo, por exemplo, por aquecimento, ou se pode ser consumido diretamente. No que diz respeito a um nível aceitável de risco para um perigo potencial de inocuidade do alimento, deve-se indicar para que grupo da população o alimento se destina. É óbvio que são necessárias maiores exigências relativas à inocuidade para hospitais ou asilos para idosos (OPAS, 2001).

\subsubsection{Implementação do APPCC}

O passo mais difícil para a indústria é, sem dúvida, o momento de introduzir o plano. As mudanças têm que ser inseridas gradativamente e da forma mais prática possível. Muitas empresas optam por fazer simulações que possam vir a ocorrer, supervisionados pelo pessoal responsável, até que todos estejam envolvidos e viabilize a nova rotina (FURTINI; ABREU, 2005).

Dentre as principais dificuldades enfrentadas para implementação do Sistema estão a capacitação técnica e os investimentos em infra-estrutura (FURTINI; ABREU, 2005).

Como exemplo de um processo de adequação de um sistema de gestão de qualidade, observou-se um estudo relatado por Spexoto et al. (2005) numa propriedade leiteira. Realizou-se a implantação de APPCC e verificou-se que as principais dificuldades encontradas no projeto foram a motivação e o envolvimento dos funcionários para a nova rotina implementada; dificuldade de tomada de decisão rápida; falta de dados indicando os limites críticos e as formas de monitoramento do trabalho, dentre outros. 


\subsubsection{ISO 22000}

\subsubsection{Sobre a ISO 22000}

A Associação Brasileira de Normas Técnicas (ABNT) é o Fórum Nacional de Normalização. A Normalização é a atividade que estabelece, em relação a problemas existentes ou potenciais, prescrições destinadas à utilização comum e repetitiva com vistas à obtenção do grau ótimo de ordem em um dado contexto (ABNT, 2006). As Normas são elaboradas por Comissões de Estudo (CE), formadas por representantes dos setores envolvidos como produtores, consumidores e neutros, no caso universidades, laboratórios e outros (ABNT, 2006).

Em setembro de 2002 foi lançada a ABNT NBR 14900 - Sistema de gestão da análise de perigos e pontos críticos de controle - Segurança de alimentos. Descreve os requisitos para uma organização implementar um sistema de gestão de segurança de alimentos segundo os princípios da APPCC, podendo ser aplicada por organizações que atuem na cadeia produtiva de alimentos (ABNT, 2006). Em 05/06/2006 foi cancelada e substituída pela NBR ISO 22000. O mesmo aconteceu com a NBR 14994 - Sistema de gestão da análise de perigos e pontos críticos de controle - Diretrizes para implementação, surgiu em novembro de 2004, para aumentar o potencial de melhoria de desempenho de uma organização e também foi cancelada em 21/08/2006.

A norma ISO 22000 - Sistema de Gestão da Segurança de Alimentos para qualquer organização da cadeia de alimentos, deu início a uma família de normas, à qual pertence a TS/ISO 22004 - Guia para aplicação da ISO 22000, além de outras que estão em elaboração (ABNT, 2006). A ISO 22000 foi desenvolvida com base no formato das normas de gestão da ISO, como por exemplo, ISO 9001 ou ISO 14001. Esta similaridade permite que as organizações implementem as especificidades do sistema de Gestão alimentar integradas no sistema de gestão da organização (gestaodainformacao.com, acessado 31/01/2007).

A importância da ISO 22000 é prover à comunidade internacional um instrumento de base para sistemas de certificação que possam ir além das fronteiras nacionais. O objetivo é diminuir a atual diversidade de sistemas de gestão de segurança dos alimentos (fooddesign.com, acessado 31/01/20007). 


\subsubsection{Cadeia produtiva e processo}

Na ABNT NBR ISO 22000 a empresa considera os efeitos da cadeia produtiva de alimentos antes e subsequentemente às suas operações quando desenvolver e implementar o sistema de gestão de segurança de alimentos (ABNT, 2006).

O planejamento e a implementação do sistema de gestão da segurança de alimentos de uma empresa dependem dos perigos relativos à segurança dos alimentos, dos produtos fornecidos, dos processos empregados, e o tamanho e a estrutura da organização (ABNT, 2006). Identificar e gerir numerosas atividades correlacionadas promove o bom funcionamento de um sistema de gestão de uma empresa. Um processo se faz quando ocorre transformação de entradas em saídas e consequentemente a saída de um processo é a entrada de um novo processo (ABNT, 2006). A identificação das interações e a gestão destes processos promovem controle contínuo sobre a ligação entre os processos individuais, bem como a sua combinação e interação. Para tal, é necessário o entendimento e o cumprimento dos requisitos, considerar os processos em termos de segurança de alimento e rastreabilidade, obter resultados da performance e eficácia do processo e melhoria contínua através de mensuração de objetivos (ABNT, 2006).

\subsubsection{Requisitos gerais}

Qualquer empresa pode implementar uma combinação de programa de prérequisitos (PPR), PPR operacionais e APPCC contanto que seja estabelecida e desenvolvida externamente em conformidade com os requisitos da NBR ISO 22000 (ABNT, 2006).

Os documentos que fazem parte do sistema convém que sejam de origem externa e devem estar disponíveis quando e onde requeridos. Retenção dos registros por períodos especificados e sob condições controladas deve ser considerada (ABNT, 2006). 


\subsubsection{Responsabilidade da direção}

O comprometimento da alta direção estabelece conscientização e liderança ao desenvolvimento e implementação do sistema. A política da segurança de alimentos como base do sistema de gestão da segurança de alimentos pode estabelecer metas e atividades mensuráveis a fim de promover melhorias do sistema (ABNT, 2006).

O próximo passo é eleger o coordenador da equipe de segurança de alimentos. Como figura central do sistema, deve ser membro da empresa, ter conhecimentos básicos em higiene e APPCC, e incluir o relacionamento com partes externas em assuntos relacionados ao sistema (ABNT, 2006).

A comunicação externa e interna deve acontecer como parte do sistema de gestão da segurança de alimentos e a interação entre ambas deve ser assegurada. O nível requerido da segurança de alimentos e a capacidade de fornecimento das informações entre a organização externa e a organização é feito por meio de comunicação externa via contrato ou outros meios (ABNT, 2006). A comunicação interna para o pessoal da organização, papel principal do coordenador da equipe, envolve desenvolvimento e lançamento de novos produtos, alterações em matériasprimas, ingredientes, sistemas e processos produtivos, clientes e requisitos de clientes, requisitos estatutários e regulamentares e perigos novos ou emergentes (ABNT, 2006).

É importante a consciência da organização sobre prontidão e resposta à emergências potenciais como inundações, incêndios, contaminação ambiental, bioterrorismo, sabotagem, etc.

A eficácia do sistema é avaliada pela análise crítica da direção sobre o desempenho da organização (ABNT, 2006).

\subsubsection{Gestão de recursos}

Treinamentos constantes e eficazes dos funcionários, infra-estrutura adequada e ambiente de trabalho com medidas para prevenir contaminação cruzada, vestuário de proteção e instalações para os empregados são condições que asseguram a manutenção do sistema de gestão da segurança de alimentos (ABNT, 2006). 


\subsubsection{Planejamento e realização de produtos seguros}

Nesta fase, considera-se o planejamento e a operação. As medidas de controle são divididas em três grupos:

a) programas de pré-requisitos (PPR) - mantêm ambiente higiênico de produção, processamento e/ou manipulação.

b) Programa de pré-requisitos operacionais (PPR operacionais) - gerenciam medidas de controle para perigos de níveis aceitáveis não gerenciados pelo APPCC.

c) Plano APPCC - gerenciam medidas de controle para controlar perigos de níveis aceitáveis aplicados nos pontos críticos de controle (PCC).

O elemento central do planejamento é a condução da análise de perigos para determinar perigos que necessitam ser controlados, o grau de controle para chegar aos níveis aceitáveis e a combinação das medidas de controle, ou seja, quais serão gerenciadas pelo APPCC e quais pelos PPR operacionais. Etapas preliminares são consideradas para conduzir a análise de perigos, como por exemplo, a origem das matérias-primas, os ingredientes e os materiais que entram em contato com o produto. $O$ fato é que especificações do fornecedor podem divergir na prática conforme o uso do produto (ABNT, 2006).

\subsection{Análise de perigos}

A identificação de perigos e determinação de níveis aceitáveis deve ser por meio de informações obtidas através de objetivos, metas ou critérios para o produto final estabelecidas pelas autoridades estatutárias e regulamentares do país de venda, ou por especificações comunicadas pela organização ou consideradas pela equipe de segurança de alimentos de acordo com a lei ou com o cliente, embasados em literatura científica e experiência profissional (ABNT, 2006).

A avaliação dos perigos pode ser feita considerando-se as fontes de perigo, a probabilidade de ocorrência do perigo, a natureza do perigo e a severidade dos 
efeitos adversos à saúde. Consideram-se também as etapas anteriores e posteriores à operação especificada, o equipamento de processo, serviços envolvidos e ambiente, bem como elos anteriores e posteriores da cadeia produtiva de alimentos (ABNT, 2006).

Em seguida, ocorre a seleção das medidas de controle e a combinação destas. É aconselhável selecionar combinações adequadas para cada um dos perigos identificados e realizar a avaliação do efeito destas medidas de controle. Quando uma medida de controle não pode ser validada, não poderá ser incluída no plano APPCC ou em PPR operacionais, mas pode ser aplicado dentro do PPR (ABNT, 2006). Para serem encaminhadas em seu respectivo grupo o processo de classificação segue alguns itens abaixo:

- impacto sobre o perigo ou freqüência de ocorrência (quanto maior o impacto maior a probabilidade de pertencer ao plano APPCC),

- a severidade à saúde do consumidor (quanto maior, maior a probabilidade de pertencer ao plano APPCC),

- a necessidade de monitorar (quanto maior, maior chance de ir para o APPCC).

\subsection{Estabelecimento dos pré-requisitos operacionais}

Pode seguir o mesmo formato usado no plano APPCC.

\subsection{Estabelecimento do plano APPCC}

O plano APPCC é estabelecido conforme já descrito anteriormente. Identificam-se os pontos críticos de controle (PCC). As medidas de controle são implementadas e gerenciadas pelo plano APPCC. Em seguida, são determinados limites críticos para os PCCs para assegurar o controle do perigo para a segurança do alimento (ABNT, 2006).

O sistema de monitoramento ideal é aquele que fornece as informações em tempo real para serem efetuados ajustes no controle do processo quando ultrapassados os limites críticos, momento em que os alimentos ficam inseguros. Nesse momento, a organização pode escolher as ações a serem providenciadas (ABNT, 2006). 
3.2.3.6.4 Atualização de informações preliminares e documentos que especificam os PPR e o plano APPCC

Nenhuma orientação é determinada.

\subsection{Planejamento da verificação}

Seguem os seguintes conceitos abaixo para melhor compreensão:

- Validação: avaliação anterior à operação - demonstra capacidade de alcançar o nível planejado de controle.

- Verificação: avaliação realizada durante e após a operação - demonstra que o nível planejado de controle foi de fato alcançado. A freqüência da verificação depende do grau de incerteza dos resultados da validação e o funcionamento da medida de controle.

- Monitoramento: procedimento de detecção de falhas na aplicação da medida de controle. 


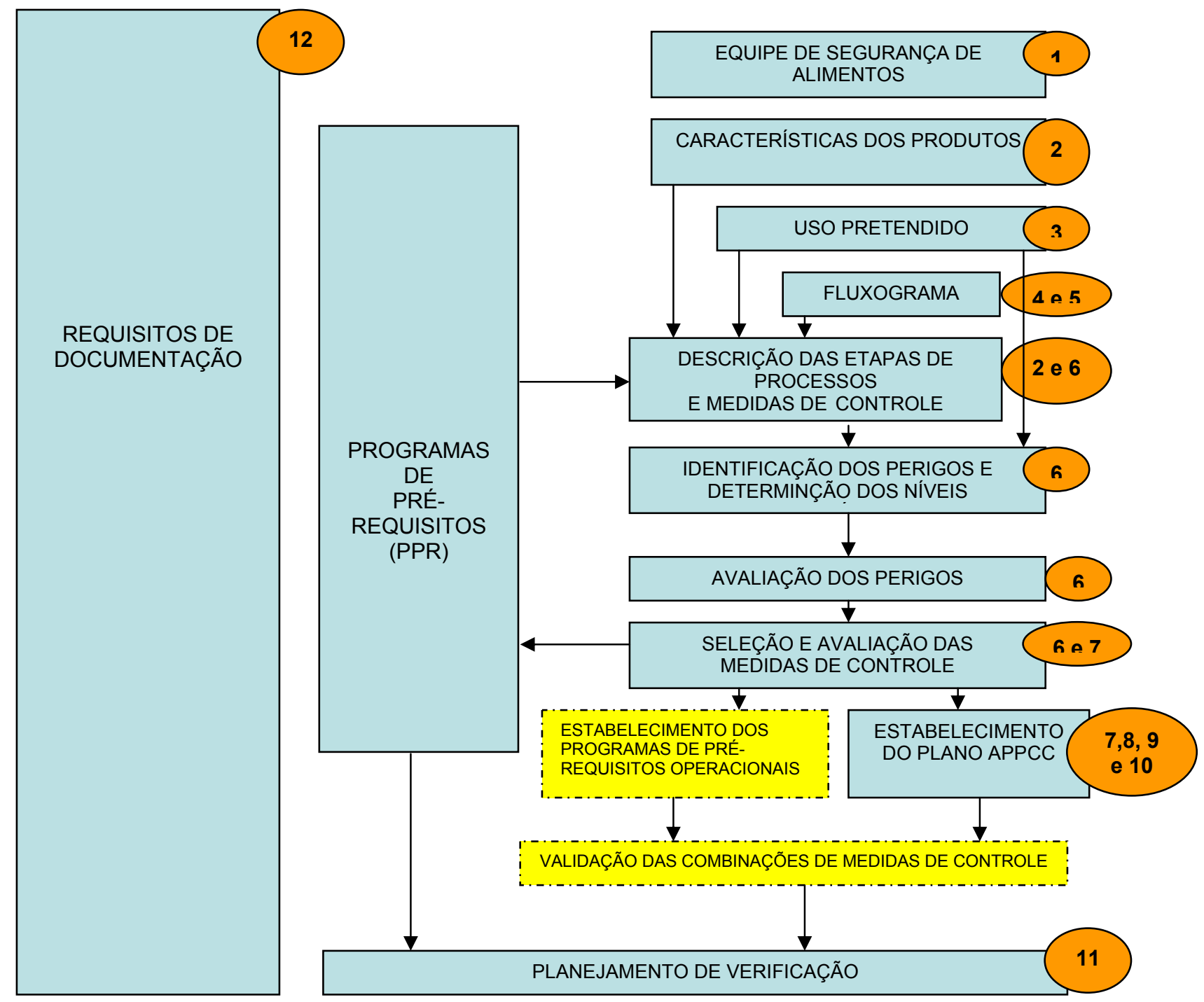

Etapas referidas pelas diretrizes da APPCC do Codex Alimentarius Etapas especificadas para ABNT NBR ISO 22000

Figura 1 - Planejamento de alimentos seguros (adaptação ABNT, 2006)

\subsection{Sistema de rastreabilidade}

O desenvolvimento da rastreabilidade se baseia em informações tais como tipos de ingredientes e seu número, reutilização de produto, material em contato com os produtos, produção em batelada ou contínua, sobreposição de lotes. Além do que, um sistema de recolhimento também deve ser considerado pela organização em caso de produtos identificados como potencialmente inseguros. 
3.2.3.7 Validação, verificação e melhoria de gestão da segurança de alimentos

Os requisitos da ABNT NBR ISO 22000:2006 incluem atividades necessárias para demonstrar que o sistema de gestão da segurança de alimentos é confiável e garante o nível de controle esperado.

O processo de validação inclui atividades como:

a) referência para validação realizada por terceiros, por literatura científica ou por conhecimento do histórico,

b) testes experimentais para simular condições de processos,

c) dados coletados de perigos biológicos, químicos e físicos durante condições normais de operação,

d) pesquisas estatisticamente planejadas,

e) modelagem matemática,

f) uso de diretriz aprovada por autoridades competentes.

A revalidação poderá ser necessária em caso de novas situações, como por exemplo medidas de controles adicionais, novas tecnologias ou equipamentos, mudanças no produto, novos perigos e/ou emergentes, alterações na sua probabilidade de ocorrência ou falhas inexplicáveis no sistema (ABNT, 2006).

Os controles de monitoramento e calibração devem ser levados em consideração. O conceito de calibração é complexo e depende do tipo de processo, de equipamento e de quanto são passíveis de calibração (ABNT, 2006).

A verificação do sistema de gestão da segurança de alimentos assegura funcionamento e atualização do processo. Duas etapas compõem a verificação: a contínua e a periódica. A primeira utiliza procedimentos isolados, além daqueles utilizados no monitoramento do sistema; a segunda envolve avaliação global do sistema, ou seja, é realizada, durante reunião da equipe de verificação, análise de todas as evidências levantadas num período de tempo. Atualizações e melhorias podem ser aplicadas caso o sistema aponte falhas no funcionamento (ABNT, 2006).

Os relatórios de verificação obtidos podem incluir dados importantes como: pessoas que administram o sistema e o atualizam, condição dos registros associados às atividades de monitoramento, garantia de que os equipamentos de monitoramento estejam adequadamente calibrados e em condições de uso, os 
resultados da análise crítica dos registros e de qualquer amostra analisada (ABNT, 2006).

Um programa de atividades de verificação considerado como parte do sistema pode incluir análise crítica dos registros de monitoramento, das ações corretivas, dos termômetros calibrados ou outros equipamentos de medição críticos; operações de inspeção visual; ensaios analíticos ou auditoria de procedimento de monitoramento; levantamentos aleatórios e análise de amostras no processo ou no produto final; amostragem relacionada ao meio ambiente e outras questões, e finalmente a análise crítica das reclamações dos consumidores e compradores (ABNT, 2006).

No quesito auditorias internas, convém que os auditores sejam independentes do sistema, embora possam ser da mesma área de trabalho. Uma alternativa para pequenas empresas é prover um auditor entre empresas ou buscar auditores terceirizados, como consultores, agentes de inspeção.

Convém que a verificação de todo o sistema seja feita anualmente para que as melhorias possam ser aplicadas (ABNT, 2006). 


\section{CONCLUSÃO}

Os alimentos devem prover nutrientes sem afetar negativamente a saúde de quem os consome. Quanto à questão da segurança, é importante que sejam livres de qualquer forma de contaminação (BRASIL, 1999a).

O presente estudo visou contribuir com o auxílio na disseminação dos conceitos da qualidade e da segurança de alimentos. Enfoque especial foi dado à ISO 22000 por ser o mais recente instrumento de gestão da segurança alimentar reconhecido internacionalmente e futuramente como requisito para nossas indústrias de produtos de origem animal que praticam a exportação, contribuindo assim para o avanço econômico do País.

Em relação à norma e o Sistema APPCC, o que se acrescentou foi o estabelecimento do programa de pré-requisitos operacionais (PPRO), os quais gerenciam medidas de controle para perigos de níveis aceitáveis não gerenciados pelo APPCC e a validação das combinações de medida de controle, tanto as destinadas para os PPRO como as estabelecidas pelo plano APPCC. Dentro das condições que incorporam a ISO 22000, para uma organizaçao obter sucesso na implementação de um sistema de gestão da segurança de alimentos é importante atender os seguintes itens:

- comunicação interativa ao longo de toda a cadeia alimentar,

- implementação de boas práticas de fabricação (ou pré-requisitos),

- controle de perigos (ou seja princípios APPCC),

- requisitos de sistemas de gestão, comuns a qualquer sistema de gestão.

No Brasil, há poucos relatos sobre a utilização de ferramentas de gestão da segurança de alimentos em indústrias de produtos de origem animal, salvo as que exportam é que contemplam exigências externas bem como leis brasileiras. Estudos deverão ser realizados para se obter um perfil geral sobre a gestão dos estabelecimentos no País. Sabemos que muitas empresas que atendem o mercado interno, por falta de informação, ainda não tomaram consciência da necessidade de se adequarem aos formatos mínimos com a implantação das Boas Práticas de Fabricação preconizada pela Resolução RDC 216/2004 para todos os estabelecimentos produtores de alimentos. Muitos casos da não utilização dessas 
ferramentas são devido ao ineficiente mecanismo de fiscalização existente no País e a falta de responsabilidade de empresários e responsáveis técnicos.

A implementação de programas de orientação e conscientização nas Indústrias no que se refere à legislação brasileira quanto às Boas Práticas de Fabricação, APPCC e outras ferramentas de gestão da segurança alimentar e, principalmente, a ação dos órgãos fiscalizadores para que a lei seja cumprida nos quesitos mínimos, é uma das formas para que alcancemos níveis de qualidade e segurança nos produtos oferecidos à população brasileira. 


\section{REFERÊNCIAS BIBLIOGRÁFICAS}

ABNT ISO/TS 22004:2006 - Sistemas de Gestão da Segurança de Alimentos: Guia de Aplicação da ABNT ISO 22000:2006. São Paulo, 2006.

BORGES, J.T.S., FREITAS, A. S. Aplicação do sistema Hazard Analysis and Critical Control Points (HACCP) no processamento de carne bovina fresca. Curitiba, 2002, Boletim Centro de Pesquisa de Processamento de Alimentos, v. 20, n.1.

BRASIL. Ministério da Agricultura, Pecuária e Abastecimento. Importância do Codex Alimentarius. Disponível em www.agricultura.gov.br. Acesso em setembro de 2006.

BRASIL a. Agência Nacional de Vigilância Sanitária - Resolução $n^{\circ}$ 17. Diário Oficial [da] União, Brasília, 30 de abril de 1999. Estabelece Diretrizes Básicas para Avaliação de Risco e Segurança dos Alimentos.

BRASIL, Ministério da Saúde. Secretaria de Vigilância Sanitária. Portaria $n^{\circ} 1.428$, de 26 de novembro de 1993. Regulamentos Técnicos sobre Inspeção Sanitária, Boas Práticas de Produção/Prestação de Serviços e Padrão de Identidade e Qualidade na Área de Alimentos.

BRASIL, Ministério da Agricultura e Abastecimento. Portaria $n^{\circ} 46$, Diário Oficial [da] União, Brasília, 10 de fevereiro de 1998. Institui o sistema de análise de perigos e pontos críticos de controle: APPCC a ser implantado nas indústrias de produtos de origem animal .

CNI/SENAI/SEBRAE. Elementos de apoio para o sistema APPCC. (Série Qualidade e Segurança Alimentar). Projeto APPCC indústria. Brasília, SENAI/DN, $2000,2^{\mathrm{a}}$ ed, $361 \mathrm{p}$.

CNI/SENAI/SEBRAE/ANVISA. Elementos de apoio: boas práticas e sistema APPCC. Rio de Janeiro: SENAC/DN, 2001. 303p 
CNI/SENAI/SEBRAE. Guia para elaboração do Plano APPCC; carnes e derivados. (Série Qualidade e Segurança Alimentar) Projeto APPCC indústria. $2^{\mathrm{a}}$ ed. Brasília, 2000, 142 p. SENAI/DN.

CODEX ALIMENTARIUS - CAC/RCP-1-1969 - Rev 3 (1997), Amd. (1999).

DIAS, D. Prática de higiene na empresa de alimentos. Cuiabá: SEBRAE/MT, 1999

FELIX, J. C., ZÜGE, R.M., VICENTINI, N.M., A certificação como ferramenta para a promoção da segurança alimentar, Recife, 2003, Metrologia para a vida (SBM).

FIGUEIREDO, V. F., COSTA NETO, P. L. Implantação do HACCP na indústria de alimentos, São Paulo, 2001, Gestão e Produção, v.8, n1, p. 100 -111.

FURTINI, L.L.R., ABREU, L.R., Comunicação utilização de APPCC na indústria de alimentos, Lavras, 2005, Ciência agrotec., v.30, n2, p.358-363.

OPAS - OMS- INPPAZ. GMP/HACCP - Boas Práticas de Fabricação e Análise de Perigos e Pontos Críticos de Controle. 2001.

PIETROWSKI, G. A. M., Avaliação do perfil do profissional que atua no monitoramento do sistema HACCP: estudo de caso em empresa de refeições coletivas no estado do Paraná. Florianópolis, 2002, Dissertação de Mestrado, Universidade Federal de Santa Catarina, $154 \mathrm{f}$.

ROCHA, C. D., Avaliação das Condições de Fabricação em Agroindústrias de Produtos de Origem Animal Localizadas no Distrito Federal. Brasília, 2006, 60 p., Monografia de conclusão de curso de Medicina Veterinária, Universidade de Brasília.

SILVA JUNIOR, E. A. Manual de Controle Higiênico-Sanitário em Alimentos. $4^{\mathrm{a}}$ ed. São Paulo: Livraria Varela, 2001. 
SPEXOTO, A. A. Aplicação do Sistema de Análise de Perigos e Pontos Críticos de Controle (APPCC) em Propriedades Leiteiras. São Paulo, 2005, Dissertação de Mestrado, Universidade de São Paulo.

THRUN, D. Sistemática do gerenciamento do processo suportado em medidas de controle para os serviços internos para uma indústria de alimentos. Florianópolis, 2003119 p. Dissertação de Mestrado, Universidade Federal de Santa Catarina.

WURLITZER, N. J. Industrialização de Alimentos Visando a Saúde do Consumidor. SENAI, Rio de Janeiro, 2007. Disponível em:

http://www.firjan.org.br/notas/media/Alimentos.PDF. Acesso em 17 mar. 2007.

Sites consultados:

http://www.Irqa.com.br/certificacao/alimentos/iso22000.asp

http://www.fooddesign.com.br/arquivos/academia/palestraisodis22000.pdf

http://www.fooddesign.com.br/3 news.php

http://www.abnt.org.br/default.asp?resolucao $=800 \times 600$

http://gestaodainformacao.com/002.aspx?dqa=0:0:0:21:0:0:-1\&ct=30

http://www.firian.org.br/notas/media/Alimentos.PDF

http://www.cve.saude.sp.gov.br/htm/notifica RAPI.htm 